\title{
Routine Pre-operative CT - ready to roll or a step too far?
}

\author{
Pradeep Narayan ${ }^{1}$ and Gianni Angelini² \\ ${ }^{1}$ Rabindranath Tagore International Institute of Cardiac Sciences \\ ${ }^{2}$ Bristol University
}

March 3, 2022

\begin{abstract}
The incidence of stroke after coronary artery bypass grafting (CABG) is around $1.3 \%$ in the Society of Thoracic Surgeons database but carries a mortality of almost $20 \%(1,2)$. The stroke rate is even higher with aortic valve replacements with the Determining Neurologic Outcomes from Valve Operations (DeNOVO) study reporting stroke rates as high as $17 \%$ (3). It is also likely that variations in definition of stroke leads to underreporting of this event. There is thus, no denying that stroke remains the Achilles heel of cardiac surgery and efforts must be made to mitigate its occurrence.
\end{abstract}

Routine Pre-operative CT - ready to roll or a step too far?

Pradeep Narayan FRCS[CTh]*, Gianni D Angelini FRCS^

* Rabindranath Tagore International Institute of Cardiac Sciences, Narayana Health, India

Word Count : 1038

Corresponding Author:

Prof GD Angelini, MD,MCh,FRCS, FMedSci

British Heart Foundation Professor of Cardiac Surgery,

Bristol Heart Institute Bristol Royal Infirmary,

Upper Maudlin Street BS2 8HW

Bristol, UK

G.D.Angelini@bristol.ac.uk

Conflict of Interest : none

Funding: This work was supported by the British Heart Foundation and the NIHR Biomedical Research Centre at University Hospitals Bristol and Weston NHS Foundation Trust and the University of Bristol.

Key words : Pre-operative CT, Stroke, CABG

The incidence of stroke after coronary artery bypass grafting (CABG) is around $1.3 \%$ in the Society of Thoracic Surgeons database but carries a mortality of almost $20 \%(1,2)$. The stroke rate is even higher with aortic valve replacements with the Determining Neurologic Outcomes from Valve Operations (DeNOVO) study reporting stroke rates as high as $17 \%$ (3). It is also likely that variations in definition of stroke leads to underreporting of this event. There is thus, no denying that stroke remains the Achilles heel of cardiac surgery and efforts must be made to mitigate its occurrence. 
The case by Osorio-Jaramillo published in this issue of the journal reignites the discussion on the value of computerised tomographic(CT) imaging as a routine pre-operative investigation prior to cardiac surgery (4). The identification of a mass on the ascending aorta led to a revision in operative strategy whereby along with the initially planned CABG, concomitant supra-coronary replacement of the ascending aorta was also performed. It is likely that in the absence of modification of surgical strategy this unexpected mass in the ascending aorta may have led to a peri-operative stroke with serious adverse outcomes.

Atheromatous disease of the aorta not only increases the risk of perioperative stroke but also impacts upon long term mortality (5-7). The stroke rate has been shown to be quadrupled in presence of an atheroma in the proximal aorta (5). Prevention of these adverse outcomes thus hinges on identification of the atheromatous aorta. While this has been attempted intra-operatively by manual palpation of the aorta the reliability with manual palpation is low with the additional risk of plaque embolization. $(7,8)$ TransEsophageal-Echocardiography(TEE) has also been used to detect atherosclerotic aorta but has limited access to the ascending aorta and arch and the sensitivity is only marginally better than manual palpation (9). Epi-aortic ultrasound is significantly better than both manual palpation and TEE and is recommended for identification of atheromatous plaques (Class IIa, level of evidence C) (10) The downside of Epi-aortic ultrasound is it being operator dependent and more importantly the information is available only after a sternotomy has been performed. Pre-operative planning and a considered discussion with the patient is thus not possible. Multidetector computed tomography (MDCT) is being used increasingly to diagnose the atheromatous aorta and its superior spatial resolution coupled with 3D reconstruction capabilities makes it an attractive option in the pre-operative setting (11).

Preoperative CT has been used in the past predominantly in the re-operative setting. Studies comparing patients undergoing re-operative surgery have reported a reduction in stroke rates in patients undergoing preoperative CT scans (12). Apart from stroke there was also a reduction in sternotomy-related injury, complication rates $(13,14)$ and this resulted in improved perioperative outcomes $(15)$. There are contradictory findings with regards the effect of pre-operative CT scans on mortality with some studies suggesting improved outcomes $(13,15)$ while others suggest an increase of mortality in these patients(12). While the findings of all these studies may be influenced by several factors and are open to questioning one fact remains indisputable that most studies report a change in either surgical access, strategy of cannulation or even operability(16). While the indication for a preoperative CT in re-operative surgery is essentially to assess the anatomical orientation of structures and especially the grafts after CABG; its role in primary cardiac surgery is to evaluate the extent of atherosclerosis of the ascending aorta and arch (16).

While the usefulness of pre-operative CT scan is intuitive, robust data on improvement with this strategy is sparse, especially in routine or low-risk patients. In high-risk patients use of pre-operative CT scan in patients undergoing cardiac surgery has been shown to be associated with a reduction in stroke rates as well as mortality (17). However, the groups compared were from two different time periods. Another study that carried out pre-operative CT scan in patients undergoing CABG except those who required emergency surgery or had renal failure demonstrated a change of strategy in nearly half the patients (18). The change in strategy included avoidance of cannulation and cross-clamping by using off -pump anaortic techniques, alteration in conduit selection and grafting strategy, as well as replacement of ascending aorta and additional procedures on the carotid and renal arteries. Besides, pre-operative CT identified malignancy in some patients as well.

The concerns with using pre-operative CT scans include radiation exposure, contrast induced nephropathy, additional cost and utilization of resources which may be an important consideration in resource depleted countries and state funded healthcare systems. Even though, ultra-low-dose CT scanning without contrast enhancement can satisfactorily identify an atheromatous aorta thus ameliorating some of the concerns the benefit of pre-operative CT scan is still not established. Studies which have compared the role of pre-operative $\mathrm{CT}$ in improving outcomes especially in primary surgery are few and suffer from considerable heterogeneity.

While some of the studies have used contrast enhanced CT scans other use non-contrast CT for reporting outcomes. Considerable variability also exists in the case-mix with CABG, valve surgeries and CABG 
with concomitant valve surgery being included in varying proportions in different studies all of which further muddy the water. Mortality has been defined at 30-day in some and as in-hospital in others making comparison across studies extremely unreliable. The definition of stroke in these studies still needs to be standardized. The current definition of stroke as recommended by the new American Heart Association/American Stroke Association statement has modified the definition such that in addition to clinical features of stroke, evidence of cerebral emboli by diffusion-weighted magnetic resonance imaging also constitutes stroke (19).

Pre-operative CT scans have shown potential and should not be dismissed however, large scale randomized studies would be needed to confirm its place in routine pre-operative evaluation of cardiac surgical procedures. The results of "Ultra low-dose chest $\mathrm{CT}$ with iterative reconstructions as an alternative to conventional chest x-ray prior to heart surgery (CRICKET study)" are awaited (NCT02173470). The study is a multi-centric randomized controlled trial comparing pre-operative Chest X-rays and those undergoing an additional preoperative non-contrast-enhanced chest CT among patients undergoing cardiac surgery (20). The outcomes studied include stroke rate and alteration of surgical strategy. Until the time more conclusive evidence is available, routine pre-operative CT scans seems a step too far and can perhaps only be justified in re-operative surgery and in patients at high risk for developing a peri-operative neurological event.

References:

1. Gaudino M, Angiolillo DJ, Di Franco A, Capodanno D, Bakaeen F, Farkouh ME, et al. Stroke After Coronary Artery Bypass Grafting and Percutaneous Coronary Intervention: Incidence, Pathogenesis, and Outcomes. Journal of the American Heart Association. 2019 Jul 2;8(13):e013032.

2. O'Brien SM, Feng L, He X, Xian Y, Jacobs JP, Badhwar V, et al. The Society of Thoracic Surgeons 2018 Adult Cardiac Surgery Risk Models: Part 2-Statistical Methods and Results. Ann Thorac Surg. 2018 May;105(5):1419-28. 1.

3. Messé SR, Acker MA, Kasner SE, Fanning M, Giovannetti T, Ratcliffe SJ, et al. Stroke after aortic valve surgery: results from a prospective cohort. Circulation. 2014 Jun 3;129(22):2253-61.

4 Osorio-Jaramillo E, Strassl A, Kocher A, Laufer G, Haberl T. Nose-shaped Mass in the Ascending Aorta. J Card Surg. 2022;

5. Roach GW, Kanchuger M, Mangano CM, Newman M, Nussmeier N, Wolman R, et al. Adverse cerebral outcomes after coronary bypass surgery. Multicenter Study of Perioperative Ischemia Research Group and the Ischemia Research and Education Foundation Investigators. N Engl J Med. 1996 Dec 19;335(25):1857-63.

6. Butler CG, Ho Luxford JM, Huang C-C, Ejiofor JI, Rawn JD, Wilusz K, et al. Aortic Atheroma Increases the Risk of Long-Term Mortality in 20,000 Patients. Ann Thorac Surg. 2017 Oct;104(4):1325-31.

7. Andersen ND, Hart SA, Devendra GP, Kim ESH, Johnston DR, Schroder JN, et al. Atheromatous disease of the aorta and perioperative stroke. J Thorac Cardiovasc Surg. 2018 Feb;155(2):508-16.

8. Royse AG, Royse CF. Epiaortic ultrasound assessment of the aorta in cardiac surgery. Best Pract Res Clin Anaesthesiol. 2009 Sep;23(3):335-41.

9. Suvarna S, Smith A, Stygall J, Kolvecar S, Walesby R, Harrison M, et al. An Intraoperative Assessment of the Ascending Aorta: A Comparison of Digital Palpation, Transesophageal Echocardiography, and Epiaortic Ultrasonography. Journal of Cardiothoracic and Vascular Anesthesia. 2007 Dec 1;21(6):805-9.

10. Sousa-Uva M, Neumann F-J, Ahlsson A, Alfonso F, Banning AP, Benedetto U, et al. 2018 ESC/EACTS Guidelines on myocardial revascularization. Eur J Cardiothorac Surg. 2019 Jan 1;55(1):4-90.

11. Akhtar NJ, Markowitz AH, Gilkeson RC. Multidetector computed tomography in the preoperative assessment of cardiac surgery patients. Radiol Clin North Am. 2010 Jan;48(1):117-39.

12. Lapar DJ, Ailawadi G, Irvine JN, Lau CL, Kron IL, Kern JA. Preoperative computed tomography is associated with lower risk of perioperative stroke in reoperative cardiac surgery. Interact Cardiovasc Thorac 
Surg. 2011 Jun;12(6):919-23.

13. Aviram G, Mohr R, Sharony R, Medalion B, Kramer A, Uretzky G. Open heart reoperations after coronary artery bypass grafting: the role of preoperative imaging with multidetector computed tomography. Isr Med Assoc J. 2009 Aug;11(8):465-9.

14. Morishita K, Kawaharada N, Fukada J, Yamada A, Masaru T, Kuwaki K, et al. Three or more median sternotomies for patients with valve disease: role of computed tomography. Ann Thorac Surg. 2003 May;75(5):1476-80; discussion 1481.

15. Goldstein MA, Roy SK, Hebsur S, Maluenda G, Weissman G, Weigold G, et al. Relationship between routine multi-detector cardiac computed tomographic angiography prior to reoperative cardiac surgery, length of stay, and hospital charges. Int J Cardiovasc Imaging. 2013 Mar;29(3):709-17.

16. den Harder AM, de Heer LM, Meijer RCA, Das M, Krestin GP, Maessen JG, et al. Effect of computed tomography before cardiac surgery on surgical strategy, mortality and stroke. Eur J Radiol. 2016 Apr;85(4):744-50.

17. Lee R, Matsutani N, Polimenakos AC, Levers LC, Lee M, Johnson RG. Preoperative noncontrast chest computed tomography identifies potential aortic emboli. Ann Thorac Surg. 2007 Jul;84(1):38-41; discussion 42.

18. Park K-H, Lee HY, Lim C, Chung ES, Sung S-W, Choi SI, et al. Clinical impact of computerised tomographic angiography performed for preoperative evaluation before coronary artery bypass grafting. Eur J Cardiothorac Surg. 2010 Jun;37(6):1346-52.

19. Sacco RL, Kasner SE, Broderick JP, Caplan LR, Connors JJB, Culebras A, et al. An updated definition of stroke for the 21st century: a statement for healthcare professionals from the American Heart Association/American Stroke Association. Stroke. 2013 Jul;44(7):2064-89.

20. den Harder AM, de Heer LM, Maurovich-Horvat P, Merkely B, de Jong PA, Das M, et al. Ultra low-dose chest ct with iterative reconstructions as an alternative to conventional chest x-ray prior to heart surgery (CRICKET study): Rationale and design of a multicenter randomized trial. J Cardiovasc Comput Tomogr. 2016 Jun;10(3):242-5. 